\title{
Analysis of Profitability and Constraints of Table Egg Production Enterprises in Benue State, Nigeria
}

\author{
Mere, C. U.; Ater, P. I. and Ezihe, J. A. C. \\ Department of Agricultural Economics, College of Agricultural Economics and Extension Federal University of Agriculture \\ Makurdi. P.M.B. 2373 Makurdi Benue State, Nigeria
}

\begin{abstract}
This study was carried out in Benue State, Nigeria. It was aimed at determining the profitability of table egg production enterprises and the constraints limiting their operations. The population of the study comprised all registered table egg production enterprises in Benue State, Nigeria. A sample size of 65 table egg production enterprises were selected using multi-stage random sampling technique. Cross sectional data were obtained from the 65 table egg producers with the aid of structured questionnaire. Data collected from the enterprises were analysed using descriptive statistics, farm budgeting technique and factor analysis methods. The results revealed that the table egg production enterprises in the state were of medium scale, with mean flock size of 1040 birds. An average producer in the enterprise was 44 years old and had a household size of 7 persons. All the producers had obtained one for of formal education or the other, with tertiary education being the majority (69.2\%). Table egg production was found to be a profitable venture in the study area with Net Farm Income (NFI) of 1248.03 per bird. However, the enterprises are faced with a number of constraints militating against their efficient operation. These including financial/marketing, inputs and environmental constraints. Based on the findings of this study, it was concluded that table egg production in the State is profitable. The enterprise remains a viable investment option for investors, as it possesses high growth potentials which are achievable through increased investment and proper management of identified constraints. Hence, subsidization of poultry production inputs by the government, making loans/grants easily accessible to egg farmers at single digit interest rates, formation of cooperative societies by the producers in the enterprise, setting up of more feed mills in the state and support for researches geared toward developing Nonfeed-food competing feed materials were recommended as means of increasing profitability of table egg enterprises in the Study area.
\end{abstract}

Keywords- Table Egg, Profitability, Production, Constraints, Benue State.

\section{INTRODUCTION}

The Poultry industry is an important branch of the livestock sub-sector of Nigeria's agricultural sector. The importance of the poultry industry lies chiefly in the provision of meat and egg, the provision of employment either directly or indirectly and the generation of revenue; Gross Domestic Product (GDP) of the country (Adebayo and Adeola, 2005). Although poultry production began as a rural and subsistence backyard farming practice, today, it has become a fully commercialized industry. It is the most commercialized (capitalized) of all the sub-sectors of the Nigerian agriculture (Adene and Oguntade, 2006).

According to Okoli et al.(2004), poultry keeping is the commonest livestock production practice in rural areas of Nigeria. They added that it is an attractive business because birds adapt easily to new and changing environmental factors, relative to other livestock. They have high economic value, rapid generation time and a high rate of productivity that can result in the production of meat within eight weeks and eggs within eighteen weeks from the time the birds are day old. In the first year of its laying life, a fowl is capable of producing about 300 eggs but under tropical conditions this has averaged about 180 - 200 eggs, even though higher levels have been reported (Oluyemi and Robert, 1978; Kumar and Pandey, 1999).

Following the drive towards the attainment of food security in Nigeria and efforts to diversify the economy from oil to non-oil sectors, following the volatility of oil prices in recent years, the agricultural sector has received and continues to so much attention by the government and private sectors. The increased in activities in the sector have led to rising rate of investment in the various subsectors, including the poultry industry. Tijjani et al. (2014) noted that despite the growth in the country's egg production industry since the year 2000, domestic egg production has is yet to meet demand. Preliminary survey showed that despite the abundant production of some livestock feed materials like soya beans and maize, Benue State still depend on neighbouring states for her egg needs. 
Literatures provide evidence of Studies on poultry egg production in different parts of Nigerian; Aihonsu (1999) assessed the optimal laying period for profitable and sustainable egg production., Tijjani et al. (2006) studied the profit efficiency among Nigerian poultry egg farmers in Ojo Area of Lagos State., Nigerai, Mukhtar (2007) analysed the economics of poultry-egg production in Bauchi Local Government Area, Bauchi State, Nigeria.,Yusuf and Malomo (2007) assessed the technical efficiency of poultry egg Production in Ogun, Nigeria., Jatto (2012) studied the economics and social characteristics of registered poultry egg Producers in Ilorin, Kwara State, Nigeria., Aji and Tanko (2011) compared the economic efficiency of broiler and egg production enterprises in Niger State, Nigeria., while Tanko et al. (2014) analyses the profit efficiency of small scale layer producers in some selected Local Government Areas in Sokoto State, Nigeria. This and many other related studies have been conducted in Nigeria, however, published information on the profitability or constraints of table egg production in Benue State is lacking. It is in this light that this study sought to determine the profitability and constraints of table egg production enterprises in Benue State, Nigeria. Specifically, the objectives of the study were to:

(i) Describe the socio-economic characteristics of table egg producers;

(ii) Determine the profitability level of table egg producers and

(iii) Identify the constraints to table egg production in the study area.

\section{METHODOLOGY}

This study was carried out in Benue Sate, Nigeria. Benue State is in the middle belt zone of Nigeria, between latitudes $8^{0}-10^{0} \mathrm{~N}$ and longitudes $6^{0}-8^{0} \mathrm{E}$, with the land mass of about $33,955 \mathrm{Km} 2$ and 23 local government areas three agricultural zones and total population of 4.2 million people (National Population Commission (NPC) (2006) and Hula (2010)). It shares boundaries with five other states, namely; Nasarawa to the North, Taraba to the East, Cross River to the South-East, Enugu to the South-West and Kogi to the West. The Republic of Cameroon shares boundary with the state on the South-East. It is bordered on the North by $280 \mathrm{~km}$ of River Benue and transversed by $202 \mathrm{Km}$ of River Katsina-Ala inland. Majority $(75 \%)$ of the population; mostly farmers reside in the rural area (Benue State Agricultural and Rural Development Authority (BNARDA), 1999). Following the administrative demarcation of the state, it is divided into three agricultural zones namely; North-east, North-west and Southern zones.
The two main ethnic groups in Benue State are the Tiv and Idoma who represent $72 \%$ and $21 \%$ respectively of the entire population. The Igede ethnic groups makes up 6 percent, while the remaining one percent is composed of the Hausa, Fulani, Jukun, Abakwa, Nyifon, Etulo and the Igbos (National Population Commission, 2006). The State is a major producer of food and cash crops like Yam, Cassava, Rice, Sesame, maize, etc. Some of the livestock produced in the state include goats, pigs, cattle and poultry. Among the livestock produced in Benue State, Poultry ranks the highest $(48.25 \%)$ in terms of population followed by goat, pig and sheep with percentage populations of $35.09 \%, 11.40 \%$ and $5.26 \%$ respectively (BNARDA, 1999).

Multi-stage sampling technique was employed in the selection of respondents for this study. First, one local government area (LGA) was purposively selected from each of the three agricultural zones, based on existing information on broiler production. These are namely Katsina-Ala from Northern East zone (Zone A), Makurdi from North West zone (Zone B) and Otukpo the Southern zone (Zone $\mathrm{C}$ ) due to the preponderance of broiler production enterprises; this was followed by the simple random selection of $80 \%$ of the broiler enterprises in each of the three (3) LGAs to give a sample size of 65 table egg production enterprises. Data were collected with the aid of structured questionnaire which was administered to the producers (managers) of the enterprises. The data obtained were analyzed using descriptive statistics, farm budget technique and factor analysis. Descriptive statistics such as mean, percentage, and frequency were used to ascertain the distribution based on their socioeconomic characteristics. Farm budget techniques such as Gross Margin and Net farm income (NFI) were used to estimate the costs and returns among broiler farmers. Gross Margin (GM) which is the difference between the total revenue and the total variable cost of production is expressed as:

$\mathrm{GM}=\mathrm{TR}-\mathrm{TVC}$

$\mathrm{GM}=$ Gross Margin

$\mathrm{TR}=$ Total Revenue

TVC $=$ Total Variable Cost.

On the other hand, Net Farm Income (NFI) which is the difference between the total revenue and total cost of production is expressed as:

$\mathrm{NFI}=\mathrm{GM}-\mathrm{TFC}$

Where;

NFI= Net Farm Income.

$\mathrm{GM}=$ Gross Margin

TFC=Total Fixed Cost.

Factor Analysis Model

$\mathrm{F} 1=\alpha 11 \mathrm{X} 1+\alpha 12 \mathrm{X} 2+* * *+\alpha \ln \mathrm{Xn}-\cdots(3)$ 
$\mathrm{F} 2=\alpha 21 \mathrm{X} 1+\alpha 22 \mathrm{X} 2+* * *+\alpha 2 \mathrm{nXn}---(4)$

$*$

$*$

$\mathrm{Fn}=\alpha \mathrm{n} 1 \mathrm{X} 1+\alpha \mathrm{n} 2 \mathrm{X} 2+* * *+\alpha \mathrm{nnXn}-\cdots(5)$

Where;

$\mathrm{F} 1, \mathrm{~F} 2, * * * \mathrm{Fn}=$ Unobserved underlying factors constraining broiler production.

$\alpha 1 * * * \alpha \mathrm{n}=$ Factor loadings or correlation coefficients.

$\mathrm{X} 1, \mathrm{X} 2, * * * \mathrm{Xn}=$ Observed variables/Constraints of table egg production

Fn $<$ Xn.

\section{RESULTS AND DISCUSSION}

Table 1 shows the socio-economic characteristics of table egg producers. The result on age showed that the mean age of the producers is 43 years with higher percentage of the farmers being relatively young and in their active age of production. The implication is that younger farmers are likely to adopt innovations faster than the older ones. The finding is in agreement with the findings of Jatto (2012) and Sani et al.(2007) who found that high percentages of poultry farmers were in their active ages.

The result on farming experience revealed a mean experience of 9.8 years, with majority $(67.7 \%)$ having 10 and below years of experience. The implication is that most of the producers have garnered production experience and are likely to be profitable in their production. This result supports the finding of Onyebinama (2004), that previous experience in farm business management enable farmers to set realistic time and cost targets, allocate, combine and utilize resources efficiently and identify production risks. The result also supports that of Olasunkanmi et al. (2013) who found that poultry farmers in Peri-urban Lagos Nigeria had farming experience spanning between 1 and 15 years.

The mean flock size of chicken table egg farmers in the study area was found to be 1040 birds. This shows that a typical table egg enterprise in the study area is of the medium scale class. The implication is that the farmer are likely not able to meet the egg needs of the inhabitants of the state. This could partly explain the reason for importation of eggs from other states to complement that produced in the state. The classification here followed that of Olorunsanya (2004) and Akinkumi et al.(1979) who concluded that a farmer who maintains at least 5000 birds is classified a large scale producer and farmers with between 500 and 4999 birds are medium scale producers, while those with less than 500 birds are said to small scale producers.

Analyses of household size of the producers showed a mean household size of 7 persons with a modal household size of range of between 6 and 10 persons. The high mean household size means that there is high availability of family labour to the enterprises in the study area. This result is in line with that of Igbalajobi et al. (2016).

The result on gender showed that majority $(78.5 \%)$ of the sampled producers were married. This shows that the producers are responsible according to the societal standard and therefore are likely to have some experience of life challenges which instils some level of discipline in making decision. This finding supports the result of Oluwatayo et al., (2008) that married farmers tend to have large family to compliment family labour to enhance production and reduce the cost of hired labour.

On educational status of the producers, the result shows that majority $(69.2 \%)$ of the producers had tertiary education indicating that they are highly educated. The implication is that the level of education of the producers will contribute significantly to their decision making. According to Obinne, (1991); Alabi and Aruna (2006) and Ndahitsa, (2008) education determines the quality of skills of farmers, their allocative abilities and how well informed they are to the innovations and technologies around them.

The result on occupational status showed that most of the respondents $(53.8 \%)$ in the enterprise were engaged in the eggs production venture as their secondary occupation. This implies that they had alternative means of income. This also explains the reason for the relatively high average off farm income obtained by producers in the enterprise.

Analysis of the off farm income of the producers showed that the mean off farm income for broiler and pullet-egg enterprises were $\$ 351,590.91$ and $\$ 113,034.17$ per annum respectively. This implies that the producers in both enterprises are likely to cushion some of the effects of their financial constraints using their off farm income. This result agrees with Amaza (2000) who noted that it is common for some farm household to engage in other nonfarming activities to complement their earnings from farming occupation for their livelihood.However, engaging in off farm production activities could reduce supervision and production efficiency of the farm. 
Table.1: Socio-economic Characteristics of Table Egg production Enterprise Owners

\begin{tabular}{|c|c|c|}
\hline Variables & Frequency & Percentage \\
\hline \multicolumn{3}{|l|}{ Age (Years) } \\
\hline$\leq 20$ & 2 & 3.1 \\
\hline $21-40$ & 25 & 38.5 \\
\hline $41-60$ & 33 & 50.8 \\
\hline 61 and above & 5 & 7.7 \\
\hline Total & 65 & 100.0 \\
\hline Mean & 43 & \\
\hline \multicolumn{3}{|l|}{ Experience (years ) } \\
\hline$\leq 10$ & 44 & 67.7 \\
\hline $11-20$ & 14 & 21.5 \\
\hline $21-30$ & 7 & 10.8 \\
\hline 31 and above & - & - \\
\hline Total & 65 & 100.0 \\
\hline Mean & 10 & \\
\hline \multicolumn{3}{|l|}{ Flock Size (No of Birds) } \\
\hline$\leq 1000$ & 44 & 67.7 \\
\hline 1001 and above & 21 & 32.3 \\
\hline Total & 65 & 100.0 \\
\hline Mean & 1040 & \\
\hline \multicolumn{3}{|l|}{ Household Size (No of Persons) } \\
\hline$\leq 5$ & 23 & 35.4 \\
\hline $6-10$ & 38 & 58.5 \\
\hline 11 and above & 4 & 6.2 \\
\hline Total & 65 & 100 \\
\hline Mean & 7 & \\
\hline \multicolumn{3}{|l|}{ Gender } \\
\hline Male & 38 & 58.5 \\
\hline Female & 27 & 41.5 \\
\hline Total & 65 & 100 \\
\hline \multicolumn{3}{|l|}{ Marital Status } \\
\hline Single & 14 & 21.5 \\
\hline Married & 51 & 78.5 \\
\hline Divorced/Separated & - & - \\
\hline Widow/widower & - & - \\
\hline Total & 65 & 100 \\
\hline \multicolumn{3}{|l|}{ Education } \\
\hline Primary & 3 & 4.6 \\
\hline Secondary & 17 & 26.2 \\
\hline Tertiary & 45 & 69.2 \\
\hline Total & 65 & 100 \\
\hline \multicolumn{3}{|l|}{ Occupation } \\
\hline Poultry production as primary occupation & 30 & 46.2 \\
\hline Poultry production as secondary occupation & 35 & \\
\hline \multirow[t]{2}{*}{ Total } & 65 & 53.8 \\
\hline & & 100 \\
\hline \multicolumn{3}{|l|}{ Off farm income ( } \\
\hline$\leq 200,000$ & 57 & 87.7 \\
\hline $200,001-600,000$ & 4 & 6.2 \\
\hline $600,001-1,000,000$ & 4 & 6.2 \\
\hline $1,000,001$ and above & - & - \\
\hline Total & 65 & 100 \\
\hline Mean & $113,034.17$ & \\
\hline
\end{tabular}

Source: Field Survey, 2016 


\subsection{Profitability of Table egg Enterprises}

Analysis of the cost and returns components of the table egg production enterprises as shown on Table 2 indicated that a table egg production enterprise spent an average of 10342.31as total variable cost per bird and 116.28 as total fixed cost per bird. An average table egg production enterprise in the study area realized a total gross income of $11,590.33$ per bird raised and kept in laying per annum in the study area. The average net profit realized per layer by the enterprise is 1248.02 . Analysis of the variable cost item showed that feed constituted about $89.95 \%$ of the total cost of production. Second and third highest contributing variable cost items were cost of labour $6.26 \%$ and cost of obtaining day old chicks $1.84 \%$ respectively. While returns from sales of eggs contributed the most $92.21 \%$ to the total revenue. Returns from sales of spent of culled birds and sales of droppings made up the remaining $7.5 \%$ and $0.20 \%$ respectively. This is in consonance with the findings of Tanko et al. (2014),
Emam and Hassan (2010), Samarend (2003) and Narahari (2002) who found that sale of eggs constituted the highest proportion of the total revenue. The average gross returns per bird of $\$ 11,590.33$ and the average net income per bird of $\$ 1,248.02$ suggest that table egg production is a profitable venture in the study area. Although these amounts are lower than those reported by Jatto (2012) and Tanko et al. (2014). This is in line with Tanko et al. (2014), Anang (2013), Adepoju (2008), Yusuf and Malomo (2007) and Samarendu (2003) who also found egg production to profitable and pointed out that price of egg, among other factors, influence the profitability of a poultry farm.

The result hasalso revealed that in table egg production, feed is an important cost component of poultry production. This is in agreement with Tanko et al. (2014), Anang (2013), Adepoju (2008) and Yusuf and Malomo (2007) who also found that, of the cost items in poultry production, cost of feed was the highest.

Table.2: Cost and Returns of Broiler and Table egg Enterprises

\begin{tabular}{lll}
\hline Cost/Returns Items & Amount(N/Bird) & \% \\
\hline Variable Costs & (A/Bird) & (\%) \\
i) Feed and Supplements & 9222.84 & 89.18 \\
ii) Foundation stock (DOC \& POL) & 219.68 & 2.12 \\
iii) Transportation & 11.78 & 0.11 \\
iv) Labour & 678.34 & 6.56 \\
v) Repairs and Maintenance & 38.50 & 0.37 \\
vi) Drugs and Vet. & 37.99 & 0.37 \\
vii) Debeaking & 16.89 & 0.18 \\
Total Variable Cost (TVC) & 10226.02 & 98.88 \\
Fixed Cost (Depreciation on fixed assets & such & 1.12 \\
feeders cages, etc.) & 116.28 & \\
Total Cost (TC) & & 100 \\
Revenue & 10342.31 & \\
i) Egg & & 92.46 \\
iii)Culled/Spent layers & 10716.78 & 7.27 \\
iv) By-Products e.g. Droppings & 842.24 & 0.27 \\
Total gross income & 31.31 & 100 \\
Gross Margin(GM) & $11,590.33$ & - \\
Net Farm Income (NFI) & 1364.32 & - \\
\hline
\end{tabular}

Source: Field Survey, 2016

DOC: Day old Chicks

POL: Point of Lay

\subsection{Constraints to Table egg production}

Table 3 shows the result for the rotated component matrix showing the extracted factors based on the responses of table egg producers on constraints to egg production. Factors 1, 2 and 3 were; financial/marketing constraint, input constraint and environmental constraint respectively.
The specific constraint variables contributing to financial/marketing constraint are inadequate finance (0.921), Theft (0.909) and Seasonal egg glut (0.916).

Inadequate finance may be due to the low equity base of table egg producers and their inability to access credit. Hence, table egg production in the study area is still 
operating on small and medium scale levels. This result conforms with those of Ovwigho et al. (2009) and Mukhtar (2007) who found inadequate finance as one of the major constraints to poultry production.

Seasonal egg glut with a factor loading of (0.916) was identified as one of the financial/marketing constraint. This confirms the findings of Adebayo et al. (2012) who found that seasonal egg glut was a constraint to poultry egg production. Government policies, low per capita income and consequently, low purchasing power, lack of adequate education, availability and affordability of close substitutes and complementary food have been identified as some of the causes of seasonal egg glut.

Theft was also identified as an institutional factor militating against egg production in the study area. The failure on the part of government to provide effective security through its security institutions, allows crime, including theft of eggs and birds to be perpetrated. This result agrees with Salman et al. (n.d.) who found that theft by workers and non-workers were among the risks faced by poultry farmers in Ibadan, Nigeria.

The variables contributing to input constraints (factor2) were high input cost (0.910), inadequate feed formulation ingredients (0.868), poor quality chicks (0.784) and inadequate storage facilities (0.760).

Increasing cost of inputs, including feed, labour, day old chicks, etc. is a major problem faced by egg producers. This reduces the producers' profit and discourages investment in the enterprise. This confirms the findings of Mukhtar (2007), Esiobu et al. (2014) and Adebayo et al. (2015) who identified high cost of inputs, especially cost of feed as an important constraint faced by poultry egg producers. Inadequate/poor feed formulation ingredient is likely to result in low productivity and in consequently, low returns.

Poor quality day old chicks puts the egg production enterprise at the risk of being less profitable and unattractive to investors. This confirms the findings of Mukhtar (2007) who found that poor quality day old chicks is among the constraints to egg production. The result also supports the claim of Esiobu et al. (2014) that poor breeds of layers is a constraint to poultry egg production.

Good quality storage facilities are necessary in egg production due to the short storage period of egg in an uncontrolled environment. Inadequate and poor quality storage facilities will amount to losses of eggs to theft, predators and spoilage. This result agrees with Esiobu et al. (2014) and Mukhtar (2007).

The specific variables that loaded sufficiently on environmental constraint are adverse weather condition (0.880) and disease outbreak (0.904).The environment which is consist of everything around man possess high implications for poultry production; some positive and others negative.

Adverse conditions of weather does have negative implications for egg production. For instance, extremely warm weather have been associated with drop in egg production, high rate of egg deterioration and outbreak of infectious diseases. This result agrees with Mirski (2012). Supporting the chief variable contributing to environmental constraint is outbreak of disease. Certain diseases tend to predominant in some climatic conditions than in others. Mirski (2012) established that there is an association between the outbreak of infectious diseases and climate change and variation in climatic factors like temperature, rainfall, humidity, etc.

Table.3: Constraints to Table egg Production

\begin{tabular}{lcll}
\hline & Components & & \\
\hline Variables & Factor 1 & Factor 2 & Factor 3 \\
\hline Inadequate finance & $0.921^{*}$ & -0.166 & 0.305 \\
Adverse weather Condition & 0.306 & -0.179 & $0.880^{*}$ \\
Inadequate feed formulation ingredients & -0.117 & $0.868^{*}$ & -0.046 \\
Poor quality chick & -0.158 & $0.784^{*}$ & -0.355 \\
High input cost & -0.169 & $0.910^{*}$ & -0.125 \\
Inadequate extension & $0.753^{*}$ & 0.011 & $0.505^{*}$ \\
Theft & $0.909 *$ & -0.235 & 0.076 \\
Seasonal egg glut & $0.916^{*}$ & -0.067 & 0.286 \\
Inadequate Storage facilities & -0.005 & $0.760 *$ & 0.046 \\
Diseases outbreak & 0.315 & -0.091 & $0.904 *$ \\
\hline
\end{tabular}

Source: Analysis of field data, 2016.

* = Significant based on Kaiser Normalization

Method: Principal Component Method

Factor 1= Financial/marketing; Factor 2= Input constraints; Factor 3= Environmental constraints 


\section{CONCLUSION}

The result of this study has shown that table egg production Benue State, Nigeria is a profitable enterprise and does have the potentials for growth and better profitability,though, the adoption of innovations, increase in the scale of operation and more efficient management. The enterprise is however faced with a number of constraints that have continued to hinder it from realising these potentials. The constraints include financial/marketing constraints, input constraints and environmental constraints.

The following recommendations were made based on the findings of this study:

i. The government should subsidize production inputs used by table egg production enterprises especially feeds.

ii. Funds in the forms of loans and grants should be made available and accessible to egg producers in the study area by government, commercial banks and other financial bodies. Where loans are provided, they should be at a single digit interest rate.

iii. Egg producers in the state should form cooperative societies which will enable them procure production inputs at relatively cheaper rates than they are able to do as individuals.

iv. All stake holders in the enterprise should do their bit at ensuring security in and around the farms. The farmer could hire trained guards to provide security for individual farms or groups of farms within the same location and

v. Modern poultry feed mills should be established in the study area by stakeholders in the sector. Also, the government and corporate bodies should provide support for researches towards the discovery of efficient and less expensive feed materials.

\section{REFERENCES}

[1] Adebayo, O.O, Adeola, R.G. (2005). SocioEconomic Factors Affecting Poultry Farmers in Ejigbo Local Government Area of Osun State. Journal of Human Ecology, 18(1):39 - 41.

[2] Adene, D.F. and Oguntade, A.E. (2006). The structure and importance of the commercial and village-based poultry industry in Nigeria. FAO (Rome) Study, October 2006. 66 pp.

[3] Adepoju, A. A. (2008). Technical efficiency of Egg Production in Osun state, International journal of Agricultural Economics and Rural Development, (1): 7-14.

[4] Aihonsu, J.O.Y. (1999). Optimal laying period for profitable and sustainable egg production in Bamiro, O. M. and Shittu A. M. (2009). Vertical Integration and Cost Behaviour in poultry Industry in Ogun and Oyo States of Nigeria.

[5] Akinwumi, J. A., Adegeye, A. J., Ikpi, A. E. and Olayide, S. O. (1979). Economic Analysis of Nigerian Poultry Industry (A study commissioned by Federal Livestock Department) Lagos.

[6] Amaza, P.S. (2000). Resource Use Efficiency in Food Crop Production in Gombe State: A PhD Thesis (unpublished) cited in Abdulsa- lam R.Y. (2010). Economics of Smallholder Irrigated Farming System in the Hadejia Nguru Wetlands of North Eastern Nigeria. M.sc dissertation (unpublished).Department of Agricultural Economics and Extension,Faculty of Agriculture, Usmanu Danfodiyo University Sokoto.

[7] Anang, B. T., Yeboah, C. and Agbolosu, A. A. (2013). Profitability of Broiler and Layer Production in the Brong Ahafo Region of Ghana. ARPN Journal of Agricultural and Biological Science, 8(5):423430.

[8] Benue State Agricultural and Rural Development Authority (BNARDA) (1999). Highlights of BNARDA'S Programmes, Makurdi. pp 1-15.

[9] Emam, A.A. and A.M. Hassan (2010). Econom- ics of egg poultry production in Khartoum State with emphasis on the open-system- Sudan; African Journal of Agricultural Research 5(18), 2491-2496.

[10] Esiobu, N.S; Onubuogu, G.C. and Okoli, V.B.N. (2014). Determinants of Income from Poultry Egg Production in Imo State, Nigeria: An Econometric Model Approach. Global Advanced Research Journal of Agricultural Science, 3(7): 186-199.

[11]Hula, M. A. (2010). Population Dynamics and Vegetation Change in Benue State, Nigeria. Journal of Environmental Issues and Agriculture in Developing Countries, 2(1): pp. 53-69.

[12] Igbalajobi, O., Fatuase, A. I. and Ajibefun I. (2012). Determinant of Poverty Incidence Among Rural Farmers in Ondo State, Nigeria. American Journal of Rural Development 1(5): 131-137.

[13] Jatto, N. A. (2005). Economics and Social Characteristics of Registered Poultry Egg Producers in Ilorin, Kwara State. Russian Journal of Agricultural and Socio-economic Sciences, 11(11): 18-23.

[14] Mirski, T. Bartoszeze, M. and Bielawska-Drózd (2012). Impact of Climate Change on Infectious Diseases. Polish Journal of Environmental Studies. 21(3): 525-532.

[15] Mukthtar, U. (2012). Economic Analysis of PoultryEgg Production in Bauchi Local Government Area, Bauchi State, Nigeria. M.Sc. Thesis. Department of Agricultural Economics and Rural Sociology, 
Faculty of Agriculture. Ahmed Bello University, Zaria $83 p p$.

[16] Narahari, D. (2002). All Layer Farms is More Economical than Chick, Grower Cum Layer Farm, Department of poultry science, Ma- dras veterinary college, India. Cited in Rajendran, K. and $\mathrm{M}$. Samarendu (2003). Comparative Economic Analysis and Constraints in Egg Production under Cage vs. Deep Litter Systems of Rearing in India, International Journal of Poultry Science 2 (2): 153158.

[17] National Population Commission. (2006). Population Census Statistics: Population Distribution by Age and Sex. Retrieved $10^{\text {th }}$ February, $2016 \quad$ from http://www.population.gov.ng/index.php/publication s/141-population-distribution-by-age-and-sex-2006census-priority-tables-vol-4

[18] Ndahitsa, M.A. (2008). Impact of Small Scale Irrigation Technologies on Crop Production by Fadama users in Niger state, 10th nation- al Annual Conference of National Associa- tion of Agricultural Economics (NAAEC).Held at university of Abuja main campus $\mathrm{p} 195$.

[19] Obinne, C.P.O. (1991)."Adoption of Improved Cassava Production Technologies by Small Farmers in Bendel State" African journal of Biotechnology 7 (9): 1227-1286.

[20] Okoli, I.C., Anyaegbunam, C.N., Etuk, E.B., Uchegbu M. C. and Udedibie, A.B.I. (2004). SocioEconomic Characteristics of Poultry Business Entrepreneurs in Imo State, Nigeria. Journal of Agriculture and Social Research. 4(2), 100 - 111.

[21] Olasunkanmi, M. B., Otunaiya, A. O. and Adejumo, I. (2013). Profit Efficiency in Poultry Production in Peri-Urban Lagos, Nigeria. International Journal of Applied Agricultural and Apicultural Research. 9 (1\&2): 120-130.

[22] Olorunsanya E. O. (2004). Egg Farming Business in Kwara State, How profitable? Agrosearch 6(1), 9 14.

[23] Oluwatayo, I.B., Sekumade A.B. and Adesoji S.A. (2008). Resource use efficiency of maize farmers in rural Nigeria. Evidence from Ekiti state, World Journal of Agricultural Science 4(1): 91-99.

[24] Onyebinama, U.A.U., (2004). Farm Business Management for Smallholder Farm Firms in Nigeria, Owerri Alphabet Nigeria Publish-ers, Nigeria.

[25] Salman, K.K., Ashagidigbi, W.M. and Jabar, K.T.(n.d.). Correlates of Risk-Aversion among Poultry Egg Farmers in Ibadan, Nigeria. Journal of Rural Economics and Development, 19 (1): 46 - 60.
[26] Sani, R.M., S.A., Musa, M.I. Daneji, M.T. Yaka- sai and O. Ayodele (2007). Cost and Returns Analysis in Poultry Production in Bauchi and Gombe metropolis area. Continental Journal of Agricultural Economics 1:14-19.

[27] Tanko, L. and Aji, D. A. (2011). Comparative Analysis of Economic Efficiency of Broiler and Egg Production Enterprises in Niger State, Nigeria. Retrieved $21^{\text {st }}$ December, 2015 from

[28] http://www.academia.edu/5926880/corrected_compa rative_analysis_of_economic_efficiency_of_broiler_ and_egg_production_enterprises_niger_state_nigeria

[29] Tanko, L., Nabil, I. A. and Maikasuwa, M. A. (2014). Profit Efficiency of Small Scale Layer Producers in some selected Local Government Areas in Sokoto State, Nigeria. International Journal of Modern Research and Review, 2(1): 52-61.

[30] Tijjani, A. A., Alimi, T. and Adesiyan, A. T. (2006). "Profit Efficiency among Nigerian Poultry Egg Farmers: A Case Study of Aiyedoto Farm Settlement, Nigeria. Research Journal of Agricultural Biological Sciences, 2(6):256-261

[31] Yusuf S. A. and Malomo O. (2007). Technical Efficiency of Poultry Egg Production in Ogun State, International Journal of Poultry Science, 6(9): 622629. 